\title{
INFLUÊNCIA DO TAMANHO E UMIDADE DO GRÃO NA EXPANSÃO DA PIPOCA SOUTH AMERICAN MUSHROOM ( 1 )
}

\author{
EDUARDO SAWAZAKI $\left({ }^{2,5}\right)$, \\ JENER FERNANDO LEITE DE MORAIS $\left({ }^{2,3}\right)$ \\ e ANTONIO AUGUSTO DO LAGO $(4,5$ )
}

\begin{abstract}
RESUMO
Utilizando sementes do cultivar de milho-pipoca South American Mushroom, obtido em 1984/85 em Campinas, SP, procurou-se avaliar os efeitos do teor de umidade e tamanho de grão na expansão da pipoca. Foram empregados tamanhos de grãos compreendidos entre as peneiras 14 e 18 e teores de umidade entre 9,4 e $19,8 \%$. Os resultados mostraram que a capacidade de expansão foi maior nos grãos menores e nos teores de umidade de 10,5 a $11,5 \%$.
\end{abstract}

Termos de indexação: milho-pipoca, grão, tamanho, umidade e capacidade de expansão.

(1) Trabalho apresentado na 37ª Reuniāo Anual da Sociedade Brasileira de Progresso da Ciência, realizado em Belo Horizonte, MG, em 10-17 de julho de 1985. Recebido para publicação em 6 de maio de 1985. nas (SP).

( ${ }^{2}$ Seção de Milho e Cereais Diversos, Instituto Agronómico (IAC), Caixa Postal 28, 13001 Campi-

( ${ }^{3}$ ) Estagiário, aluno de graduação do Curso de Agronomia, UNESP, Jaboticabal, no perfodo 7/1-1\%/2/1985.

(4) Seçä̃o de Sementes, IAC.

(5) Com bolsa de suplementaçáo do CNPq. 


\section{INTRODUÇÃO}

O milho-pipoca é exclusivamente utilizado para consumo humano na forma de pipoca, obtida pelo estouro que produz quando submetido a temperaturas em torno de $180^{\circ} \mathrm{C}$. Sua capacidade de estourar é explicada por ZINSLY \& MACHADO (1978) como sendo devida à resistência do pericarpo, associada à presença, no grão, de óleo e umidade. Estes componentes, quando aquecidos, exercem pressão sobre o pericarpo até que este se rompa, expondo o endosperma.

Vários métodos tem sido utilizados para medição da expansão do milho-pipoca, sendo a relação entre o volume de pipoca e o volume de grãos, denominada "capacidade de expansāo", universalmente empregada (BRUNSON, 1955). Além do fator genético, a expansão da pipoca é afetada pela umidade do grão (ALEXANDER \& CREECH, 1977; BRUNSON, 1955; ELDREDGE, 1949; HUELSEN \& BEMIS, 1955; JUGENHEIMER, 1976; ZINSLY \& MACHADO, 1978), temperatura do pipocador (BRUNSON, 1955), grau de dano no pericarpo e endosperma e método de secagem (ALEXANDER \& CREECH, 1977). A capacidade de expansão também é particularmente afetada pelo tamanho e forma dos recipientes utilizados para a medição e do grau de compressão da pipoca no recipiente (BRUNSON, 1955).

O teor de umidade é o fator que mais afeta a expansão da pipoca, variando o teor ideal com o tamanho do grão (JUGENHEIMER, 1976) e com o cultivar (ZINSLY \& MACHADO, 1978). Dados encontrados na literatura sobre 0 teor de umidade que proporciona máxima expansão da pipoca são muito variáveis, entre 11 e $15 \%$ (BRUNSON, 1955). Essas variações, em parte, podem ser devidas ao método utilizado para obtenção do teor de umidade. Estudos realizados por BACCHI \& ZINK (1970), comparando diversos métodos, mostraram que o teor de umidade de grāos de milho de $11,5 \%$, dado pela estufa a $105^{\circ} \mathrm{C}$ por 24 horas, correspondeu a $12,8 \%$ no Universal e $13,7 \%$ no Steinlite.

WLLIER \& BRUNSON (1927) observaram que a capacidade de expansão teve uma variação muito grande com o peso de cem grãos, diminuindo de 24,2 para 6,0 à medida que esse peso aumentou de 11,6 para 15,5 gramas.

A variedade South American Mushroom, lançada comercialmente em 1946, é, provavelmente, o cultivar mais plantado no Estado de São Paulo, e está sendo melhorada por seleção massal, visando principalmente ao aumento da capacidade de expansão. Diante da diversidade dos dados de literatura quanto ao teor de umidade ideal para máxima expansão da pipoca, e possibilidade de interação com tamanho de grão e cultivar, realizou-se o presente trabalho, que teve por objetivo o estudo do efeito do tamanho e umidade do gnão na capacidade de expansão dessa variedade. 


\section{MATERIAL E MÉTODOS}

Foram utilizadas sementes da variedade de milho-pipoca South American Mushroom (SAM), obtidas no Centro Experimental de Campinas, no ano agricola de 1984/85.

As sementes foram divididas em quatro frações (tratamentos), de acordo com o tamanho do grão, classificados nas peneiras 14 e 15 ( $(1), 16$ ( $($ 2), 17 ( $($ 3) e 18 ( $($ 4). Cada fração foi dividida em quatro subfrações correspondentes a diferentes teores de umidade, obtidas pela secagem em um secador do tipo ar forçado e com temperatura controlada a $35^{\circ} \mathrm{C}$.

Os teores de umidade de cada tratamento constam do quadro 1 , e foram determinados em estufa elétrica de desidratação, com ventilação adequada, mas não forçada, a uma temperatura de $105 \pm 3^{\circ} \mathrm{C}$ por 24 horas, em duas repetições de aproximadamente 25 gramas, sendo as porcentagens calculadas com base no peso úmido (BRASIL, 1980).

Para obtenção da pipoca (expansão), utilizou-se um pipocador fabricado pela Ideal, onde foi adaptado um termostato com o sensor de temperatura instalado abaixo do prato e ao lado das resistências. Foi adotada a regulagem de $300^{\circ} \mathrm{C}$, que, em testes preliminares, proporcionou maior capacidade de expansão da pipoca.

Para cada amostra efetuaram-se quatro repetições para a determinação da capacidade de expansão (C.E.), sendo esta obtida pela relação do volume de pipoca medido em uma proveta de $1.000 \mathrm{~cm}^{3}$, e o volume de $30 \mathrm{~cm}^{3}$ de grãos, medido numa proveta de $100 \mathrm{~cm}^{3}$.

QUADRO 1. Teores de umidade de sementes de milho-pipoca do cultivar SAM obtidos em cada tamanho de grão

\begin{tabular}{lllcr}
\hline \multirow{2}{*}{ Tamanho de grão } & \multicolumn{4}{c}{ Teores de umidade do grão } \\
\cline { 2 - 5 } & 1 & 2 & 3 & $4\left({ }^{1}\right)$ \\
\hline & $\%$ & $\%$ & $\%$ & $\%$ \\
T 1 - peneiras 14 e 15 & 9,4 & 10,5 & 12,5 & 16,2 \\
T 2 - peneira 16 & 9,6 & 11,1 & $12,5(13,3)$ & 18,0 \\
T 3 - peneira 17 & 9,9 & $11,2(11,4)$ & $12,4(13,3)$ & 19,0 \\
T 4 - peneira 18 & 9,7 & $11,5(11,7)$ & 12,5 & 19,8 \\
\hline
\end{tabular}

(1) Teores de umidade da amostra inicial, sem secagem.

Obs.: Os teores de umidade entre parênteses só foram utilizados para confecção da Figura 1. 
Posteriormente, utilizando-se outra amostra de grãos, com teor de umidade em torno de $9,0 \%$, separaram-se os grãos nos quatro tratamentos quanto ao tamanho, determinando-se em duas repetições o peso de cem grãos e o número de grãos contidos em um volume de $30 \mathrm{~cm}^{3}$ (Quadro 2).

Os dados foram analisados segundo esquema inteiramente casualizado com subparcelas, de acordo com o modelo recomendado por GOMES (1970). Para análise estatística, foram consideradas apenas as subparcelas 1, 2 e 3, cujos teores de umidade foram equivalentes entre os tratamentos, sendo a subparcela 4 descartada por apresentar grande variação entre os tratamentos quanto aos teores de umidade.

QUADRO 2. Características dos tratamentos (tamanho de grăo) quanto ao peso de cem grãos e número de grãos em um volume de $30 \mathrm{~cm}^{3}$

Tamanho de grão
Peso de cem grãos $\left({ }^{1}\right)$
Grãos em $30 \mathrm{~cm}^{3}$

\begin{tabular}{lcc}
\hline & $\mathrm{g}$ & $\mathrm{n}$ - \\
T 1 - peneiras 14 e 15 & 14,1 & 173 \\
T 2 - peneira 16 & 17,4 & 144 \\
T 3 - peneira 17 & 19,7 & 121 \\
T 4 - peneira 18 & 22,7 & 108 \\
\hline
\end{tabular}

(1) Com 9,0\% de umidade.

\section{RESULTADOS E DISCUSSÃO}

Os resultados obtidos mostraram diferenças significativas entre tamanhos de grãos e entre teores de umidade na capacidade de expansão (Quadro 3 e Figura 1). A interação "tamanho de grão $x$ teor de umidade" não foi significativa. A expansão foi maior nos grãos menores e nos teores de umidade compreendidos entre 10,5 e $11,5 \%$.

Utilizando-se os dados dos quadros 2 e 3 , calculou-se o volume de pipoca obtido em cem grãos para cada tratamento, com teor de umidade da subparcela 2 $(10,5$ a $11,5 \%)$. Verificou-se que o volume de pipoca amentou com o tamanho do grão, variando de $473 \mathrm{~cm}^{3}$ ( $\left(\mathrm{T}\right.$ 1) a $650 \mathrm{~cm}^{3}$ ( $T$ 4). O fato de a capacidade de expansão ter sido maior nos grāos menores deve-se ao maior número de grãos que ocorre num volume de $30 \mathrm{~cm}^{3}$, compensando a desvantagem na expansão. 


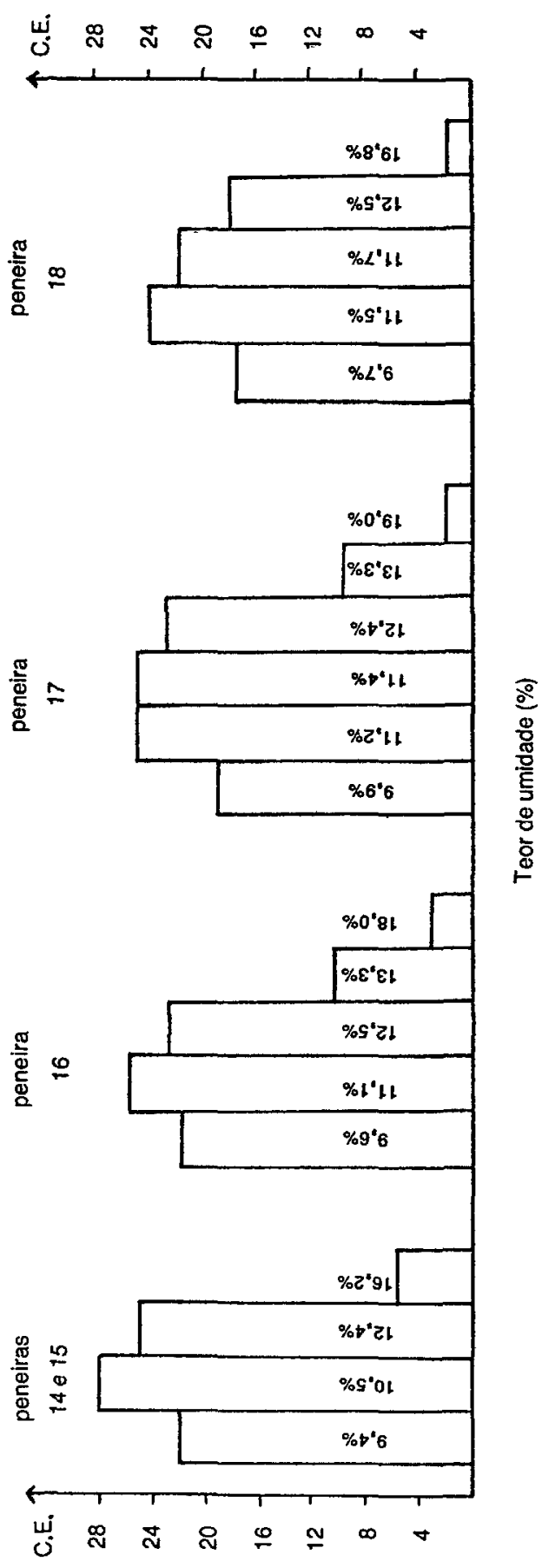

亭 
QUADRO 3. Médias da capacidade de expansão (C.E.) para diferentes teores de umidade e tamanho de grão, para o cultivar de milho-pipoca South American Mushroom. Campinas, 1985

\begin{tabular}{lcccc}
\hline & \multicolumn{3}{c}{ Teores de umidade } & Média \\
\cline { 2 - 5 } Tamanho de grão & $9,4-9,7$ & $10,5-11,5$ & $12,4-12,5$ & \\
\hline & $\%$ & $\%$ & $\%$ & $\%$ \\
Peneiras 14 e 15 & 21,8 & 27,3 & 24,5 & 24,5 a \\
Peneira 16 & 21,3 & 25,6 & 22,2 & 23,0 b \\
Peneira 17 & 19,0 & 24,2 & 22,2 & $21,8 \mathrm{c}$ \\
Peneira 18 & 17,3 & 23,4 & 17,4 & 19,3 d \\
\hline Média & 19,9 & 25,1 & 21,6 & 22,2 \\
C.V. de parcela $=4,6 \%$ & o & C.V. de subparcela $=5,7 \%$ & \\
\hline
\end{tabular}

Obs.: As médias seguidas da mesma letra, na linha e coluna, não diferem entre si ao nível de $5 \%$ pelo teste de Duncan.

Os resultados não permitiram chegar a uma determinação exata do teor de umidade em que ocorre a máxima expansão da pipoca para cada tamanho de grão. Para tanto, seria preciso haver variações nos teores de umidade, com intervalos de pelo menos $0,5 \%$. Trabalho com essa característica foi feito por WLLIER \& BRUNSON (1927), que utilizaram grãos da variedade de milho-pipoca White Rice, com vinte diferentes teores de umidade, compreendidos entre $6,3 \mathrm{e}$ $17,0 \%$, e obtiveram uma curva de distribuição normal com os valores da C.E., onde o máximo correspondeu à umidade de $12 \%$.

Com o teor de umidade de $13,3 \%$, houve acentuada queda da C.E., devido ao aparecimento de piruás e pipocas pequenas mal expandidas, o que discorda dos resultados apresentados por ELDREDGE (1949), que obteve a maior expansão da pipoca no teor de $14 \%$. Outros autores, como BRUNSON (1955) e HUELSEN \& BEMIS (1955), também citam teores de umidade acima de $13 \%$ como sendo ideal para expansão do milho-pipoca.

O menor valor do teor de umidade ideal para expansão do cultivar South American Mushroom, obtido neste experimento, pode ser devido às suas características e ao método utilizado para a determinação da umidade. 


\section{CONCLUSÕES}

1) A capacidade de expansão variou com o tamanho do grão, atingindo maiores valores nos grãos menores.

2) Para os diversos tamanhos de grão, o teor de umidade adequado para a máxima expansão da pipoca, no cultivar South American Mushroom, situou-se entre 10,5 e $11,5 \%$.

\section{SUMMARY}

\section{INFLUENCE OF SIZE AND MOISTURE OF GRAIN ON THE POPPING EXPANSION OF THE CULTIVAR SOUTH AMERICAN MUSHROOM POPCORN}

The effect of grain size and moisture on the popping expansion of popcorn was evaluated for the cultivar South American Mushroom, produced in 1984/85, in Campinas, São Paulo, Brazil. Grain size classes ranging from $14 / 64$ to $18 / 64$ inch, and moisture contents from 9.4 to $19.8 \%$ were studied. The results indicated a higher expansion rate for the smaller grains and for moisture contents between 10.5 and $11.5 \%$.

Index terms: popcorn, grain size and moisture, popping expansion.

\section{REFERÊNCIAS BIBLIOGRÁFICAS}

ALEXANDER, D.E. \& CREECH, R.G. Breeding special industrial and nutritional types. In: SPRAGUE, G.F., ed. Corn and corn improvement. 2.ed. Madison, Wisconsin, American Society of Agronomy, 1977. p.363-390.

BACCHI, O. \& ZINK, E. Teor de umidade em sementes: comparação de resultados obtidos com o emprego de diferentes métodos. In: SEMINÁRIO BRASILEIRO DE SEMENTES, 3., Recife, 1970. Anais. Recife, MA/CONTAP/USAID/ETA, 1970. p.104-105.

BRASIL. Ministério da Agricultura. Divisão de Sementes e Mudas. Regras para análise de sementes. Brasilia, 1980. 188p.

BRUNSON, A.M. Pop corn. In: SPRAGUE, G.F., ed. Corn and corn improvement. New York, Academic Press, 1955. p.423-439.

ELDREDGE, J.C. Better popping popcorn. Iowa Farm Science, 3(9):6-7, 1949.

GOMES, F.P. Curso de estatística experimental. 4.ed. Piracicaba, Nobel, 1970. 430p.

HUELSEN, W.A. \& BEMIS, E.W.P. Artificial drying and rehydration of popcorn and their effects on popping expansion. Urbana, Illinois, Agric. Exp. Sta., 1955. 68p. (Bulletin, 593) 
JUGENHEIMER, R.W. Corn improvement, seed production and uses. New York, John Wiley, 1976. 670p.

WILLIER, J.G. \& BRUNSON, A.M. Factors affecting the popping quality of popcorn. Journal of Agricultural Research, 35(7):615-624, 1927.

ZINSLY, J.R. \& MACHADO, J.A. Milho-pipoca. In: FUNDAÇĀO CARGILL. Melhoramento e produção do milho no Brasil, coord. por E. Paterniani. Piracicaba, ESALQ, 1978. p.339-347. 